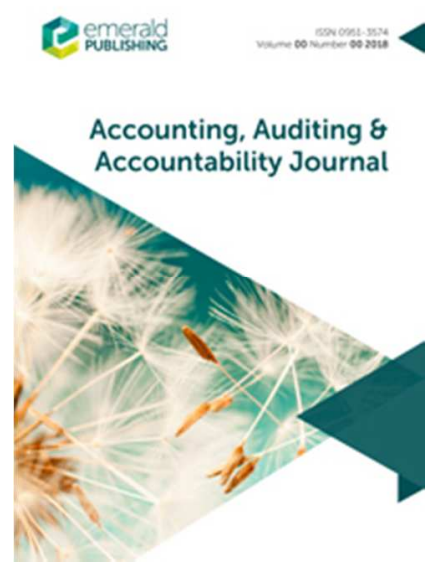

Evaluating the Integrated Reporting journey: insights, gaps and agendas for future research

\begin{tabular}{|r|l|}
\hline Journal: & Accounting, Auditing \& Accountability Journal \\
\hline Manuscript ID & AAAJ-04-2018-3446.R1 \\
\hline Manuscript Type: & Research Paper \\
\hline Keywords: & $\begin{array}{l}\text { Integrated Reporting, Idea Journey, IIRC, Development of Integrated } \\
\text { Reporting, Case studies }\end{array}$ \\
\hline \multicolumn{2}{|l}{} \\
\hline
\end{tabular}

SCHOLARONE ${ }^{\text {I }}$

Manuscripts 


\title{
Evaluating the Integrated Reporting journey: insights, gaps and agendas for future research
}

\begin{abstract}
Purpose

The aim of the paper is to identify key challenges, opportunities, strengths and weaknesses experienced by the integrated reporting idea since the IIRC's Discussion Paper was published in late 2011. It provides insights into the phases of the integrated reporting journey as investigated by accounting researchers, identifies important gaps in the literature, and sketches an agenda for future research.
\end{abstract}

\section{Design/methodology/approach}

The paper develops a theoretically informed analysis of published integrated reporting research articles using the Idea Journey theoretical framework. The paper draws upon academic analysis and insights published in 65 integrated reporting related articles across 83 accounting journals listed in the Scopus database.

\section{Findings}

A key insight of the paper is that the academic literature has not yet covered all stages of the integrated reporting idea journey. The highest proportion of articles provide insights in the generation and production phases of this journey, while there is relatively little research into the impact phase of the integrated reporting idea. Furthermore, the locus of research covered by the current integrated reporting literature is situated at macro- and meso-levels. This reveals opportunities for future research to explore, at a more detailed level, interactions between single individuals or small groups in implementing or understanding the integrated reporting idea.

\section{Research limitations/implications}

This paper focuses on the idea journey of the IIRC's version of IR. It identifies gaps regarding the stages of the integrated reporting idea journey that have not been covered by the extant academic literature and suggests some research areas that need to be addressed to help inform improvements in policy and practice. A key limitation is that it draws on a single communication channel, namely academic articles published in accounting journals, but it provides opportunities for considerable further developments.

\section{Originality/value}

The paper extends integrated reporting research by reconciling insights from an understandably fragmented emerging literature. It provides a multi-dimensional perspective on integrated reporting, highlighting the dynamics and interrelationships in the literature. It also helps inform improvements in research, policy and practice by identifying gaps 
regarding the stages of the integrated reporting idea journey that have not been covered by the extant academic literature. Lastly, the paper builds on the work of innovation and creativity scholars showing how the idea journey framework can be used to shape and add coherence to accounting research.

Keywords: Integrated Reporting, Idea Journey, IIRC, development of Integrated Reporting, case studies.

Type: Research paper 


\section{Evaluating the Integrated Reporting journey: insights, gaps and agendas for future research}

\section{Introduction}

Integrated reporting (IR) has evolved rapidly since the International Integrated Reporting Committee (IIRC - subsequently renamed the International Integrated Reporting Council) was founded in 2010 (Fries et al., 2010) and since its initial discussion paper was published in late 2011 (IIRC, 2011). In 2015, the IIRC's then CEO, Paul Druckman, used a journey metaphor to explain developments in IR practice:

[IR] is a journey and it will take more than one reporting cycle to get there. As businesses start to use [IR] as a tool to better understand the connections between key resources and relationships that contribute to their success, and as a result make more informed decisions, the real value of integrated thinking and the integrated report will be realized (IIRC, 2015).

As IR practices have now had time to mature and become more widely adopted, this seems an opportune time to analyze and reflect upon the progression of IR. A structured analysis can help identify the nature of the challenges, successes, strengths and weaknesses that IR experienced across the whole of its journey (to date) in a way that might not be as clear when examining individual stages in the IR journey. The aim of this paper, therefore, is to analyze the overall IR journey to highlight these challenges, successes, strengths and weaknesses. While there are multiple versions of IR (e.g. as developed by Eccles et al. (2010) and in earlier iterations of the King Code), this paper will focus on the specific version of IR outlined in the IIRC's (2013) International IR Framework. This paper contributes additional insights to those provided in earlier reviews of the rapidly emergent IR academic literature, which synthesized research evidence on specific aspects of this IR journey (see, for example, de Villiers et al., 2014; de Villiers et al., 2017a; de Villiers et al., 2017b; Dumay et al., 2016; Velte and Stawinoga, 2017).

To achieve its aim, the paper analyzes published IR research studies and uses the Idea Journey theoretical framework (Perry-Smith and Mannucci, 2017) to structure analysis of insights from these studies. The Idea Journey framework sets out five main phases of journey in the development and implementation of an idea. These are: idea generation, idea elaboration, idea championing, idea production and idea impact. At the time this study was undertaken, 83 journals listed in the Scopus database included the words accounting, auditing, disclosure, tax and/or accountability in their titles. We found that 65 IR-related articles were published in these journals from 2012 to 2017. A key insight from the theoretically informed analysis of this literature is that there is a lack of published research into IR at the final journey phase of idea impact - however other papers in this special issue of $A A A J$ do now provide new insights into this phase of the IR idea journey, as summarized in this paper. 
In addressing its aims, the paper proceeds as follows. Section 2 provides a brief overview of IR as the context for the issues explored in the paper. Section 3 outlines and develops the idea journey theoretical framework. Section 4 then explains the methods used to capture and analyze insights from existing literature using the idea journey theoretical framework. Section 5 analyzes insights from existing IR literature using the idea journey theoretical framework in a way that explicitly identifies connections and gaps in these insights. Section 6 summarizes insights from other articles published in this special issue of $A A A J$ that begin to address a major gap identified in the analysis of the existing literature. The final section draws conclusions and sketches an agenda for future research based on insights emerging from the analysis in this paper.

\section{Overview of Integrated Reporting}

According to the IIRC: "an integrated report is a concise communication about how an organization's strategy, governance, performance, and prospects, in the context of its external environment, lead to the creation of value in the short, medium and long term" (IIRC, 2013, p.7). The aim of an integrated report is to provide managers, investors and other stakeholders with information about several interrelated dimensions that affect or can be affected by organizations. These include: the external environment, six forms of capital employed to create value (suggested as: financial, manufactured, intellectual, human, social and relationship, and natural) and the value creation process (which describes how organizations interact with both the external environment and the capitals (de Villiers and Hsiao, 2018)).

An integral component of the value creation process is the concept of integrated thinking. The IIRC defines integrated thinking as "the active consideration by an organization of the relationships between its various operating and functional units and the capitals that the organization uses or affects" $(2013$, p. 2$)$. Integrated reporting and thinking are promoted as a practice aimed at helping companies address pressing environmental, social, and governance issues in ways that enable them to prosper over the long term to the benefit of both their shareholders and society at large (Eccles et al., 2015).

The IR framework aims to support organizations in discharging complex and interdepended duties of accountability to those who are demanding an account of impacts of companies' and other organizations' activities (de Villiers and Maroun, 2018). In so doing, IR incorporates novel ideas on disclosure that seek to contribute to the ability of organizations to provide an account to providers of financial capital, stakeholders and the broader society in a single report, and in a concise manner, covering material relationships between various operating and functional units and the nature of the resources they use or affect, (IIRC, 2013).

Since the release of the IIRC's "International <IR> Framework" in December 2013, accounting firms, corporations, public sector organizations and professional bodies across the world have shown growing interest in IR (de Villiers et al., 2014; de Villiers et al., 2017a; de Villiers et al., 2017b; Dumay et al., 2016). However, despite these developments, the 
exact purpose of IR is contested (Flower, 2015). Eccles et al. (2015, p. 8), for example, argue that while the "connectivity of information" is the essence of IR, its meaning, message and audience has evolved over time. From efforts of individual companies, through the establishment of basic principles of IR practices, to forms of codification and institutionalization aimed at supporting the implementation of an agreed-upon IR concept, supported by principles and guidelines. The IR concept is also contested (Brown and Dillard, 2014; Higgins et al., 2014; van Bommel, 2014), with a growing academic debate discussing challenges associated with implementation of the IR framework (Dumay et al., 2017; McNally et al., 2017). Despite IR being adopted internationally by a network of organizations comprising over 1,750 participants across a wide range of sectors, the framework has not yet achieved the IIRC's vision of becoming the corporate reporting norm, and the IIRC has set out plans to expand the pace and scale of IR adoption (IIRC, 2017).

To broaden the adoption of the framework, in March 2017 the IIRC launched a global consultation aimed at assessing the 'successes and challenges' of IR (IIRC, 2017). One of the findings in the resulting summary report pointed to the lack of guidance and leading practice examples as the main reasons for the struggle with the meaningful implementation of IR within organizations

In helping identify areas where academic studies could provide robust evidence of developing IR practices, a comprehensive analysis of developments of IR throughout its journey has the potential to provide academics, regulators and reporting organizations a foundation upon which to keep building their IR research, policies, and practice. With this in mind, the following section presents and develops the theoretical framing that has been used to inform analysis of the empirical material in this paper.

\section{Developing the idea journey theoretical framework}

This paper conceptualizes and analyzes the development of IR as an 'idea journey'. The 'idea journey' is "the path followed by a novel idea from its conception to its successful dissemination" (Perry-Smith and Mannucci, 2017, p. 55). The theory was initially developed in the innovation and creativity literature to provide an analytical tool that could inform "how and when a novel idea either successfully moves through the entire journey, ultimately changing the field, or gets "stuck" in any one phase or loop between phases" (Perry-Smith and Mannucci, 2017, p. 54). While alternative approaches have been outlined before (Guthrie et al., 2012; Dumay et al., 2018), this conceptualization in this field is novel and is used in this paper to assist in structuring analysis of the academic literature on IR within the accounting domain. It thereby helps surface valuable insights into the types of questions and areas of insight that IR accounting researchers have investigated, and helps identify lacunas in the literature.

The idea journey comprises a sequence of phases starting with idea generation and then progressing through idea elaboration and idea championing, ending in idea implementation. The idea generation phase is the process of generating a novel and useful idea. This phase concludes when a single, novel idea that is deemed "more promising, useful, or valuable than others" (Perry-Smith and Mannucci, 2017, p. 55) is selected. The idea that is selected 
toward the end of this phase is merely a vague idea or core concept to be elaborated upon in future phases. Analysis later in this paper demonstrates that, in the context of IR, the idea for this new accounting and reporting framework was shaped by a variety of different elements.

The idea elaboration phase involves "systematically evaluating a novel idea's potential and further clarifying and developing the idea [...] During this phase, the idea moves from a vague concept [...] to a more developed form that is sharable with others" (Perry-Smith and Mannucci, 2017, p.57). In IR's elaboration phase, after the idea of an IR framework was incorporated in the IIRC's Discussion Paper, concepts were elaborated through a multistakeholder engagement consensus-building process that culminated in the publication of the "International <IR> Framework" in 2013 (IIRC, 2011; 2013).

The idea championing phase "is the active promotion of a novel idea, aimed at obtaining approval to push the idea forward" (Perry-Smith and Mannucci, 2017, p.58). At this stage, the idea is launched into the field, articulating a compelling case in its favour and underlining the positive impact it would have on organizations and/or the field. In this phase, for IR to fulfil the IIRC's long-term vision and transform IR into the worldwide norm for corporate reporting, the IIRC needed the consistent support of a wide range of institutions and organizations in a variety of fields.

The final phase, idea implementation, can be divided into two sub-phases: idea production and idea impact (Perry-Smith and Mannucci, 2017). During the idea production sub-phase, the idea is turned into something tangible. This sub-phase includes provision of detailed steps to follow in converting the idea into a finished product, service, or process. For example, an organization that decides to adopt IR may provide internal support and practical training that helps the IR production team convert the ideas in the IIRC'S IR framework into an actual integrated report. During the idea impact sub-phase, the new idea is accepted, recognized, and used by organizations in the field. If an idea gets though the production and impact sub-phases, changing existing standards and becoming a new creative reference point for the field, the idea is then regarded as having successfully affected the field. For example, to be considered successful, IR cannot just be turned into a physical artefact in the form of published integrated reports, but may also need to be recognized widely by organizations in the field through awards and rankings of these reports.

Journeying is an allegory often promoted in business discourse to symbolize organizational adaptation, learning and advancement (IIRC, 2015; KPMG, 2013; WBCSD, 2014; Morgan, 2006). However, despite its popularity, the journey metaphor has been criticized for its ambiguity. For example, Milne et al. (2006, p.825) argue that "through adopting an infinite process approach implying progress over time, [organizations] can continue to defer addressing key moral issues". One risk of this framing, especially in the IR context where the IIRC is currently seeking to extend the impact of the IR framework (with mixed results), is that it might be read to imply an inevitable progression from generation to impact. This paper does not want to suggest that. While we deal with five sequential phases of the idea journey framework, we use these phases as heuristics for developing an understanding of 
how (i.e. progressing through phases or looping between phases) and to what extent (i.e. moving across the entire journey or being abandoned prematurely) a novel idea develops.

The use of idea journey phases to conceptualize the development of the IR field not only illuminates the problems and issues researchers are investigating, but also helps identify gaps. The next section outlines the research method that was used to collect, analyze and structure the data into the five stages of the idea journey framework.

\section{Method}

To determine the broad areas and foci of research covered by IR research published in peerreviewed accounting journals over the six-year period 2012 to 2017 firstly required identification of which journals should be included in the study. Given the quality of filtering criteria used in selecting journals for inclusion in the Scopus database, it was decided to analyze IR articles published in accounting journals within Scopus. For this purpose, we identified 83 Scopus listed journals that included the words accounting, auditing, disclosure, tax and/or accountability in their title.

A search was undertaken from these 83 journals for the period January 2012 to December 2017. The length of time was important to investigate phases of the IR idea journey. The IIRC's Discussion Paper Towards Integrated Reporting was launched at the end of 2011 bringing together "world leaders from the corporate, investment, accounting, securities, regulatory, academic, civil society and standard-setting sectors to develop a new approach to reporting" (IIRC, 2011), outlining the steps towards IR's future development and adoption. Although the IIRC had been formed in 2010, and there had been earlier versions of IR pre-dating the IIRC's formation, the 2011 discussion paper represented the first widespread dissemination of the IIRC's vision of IR so represented the first stage of the idea journey for this version of IR. The end point of December 2017 was chosen on the pragmatic basis that this was the last possible date to capture data before completing this paper.

To identify IR articles from the corpus of all articles published in these journals over the 6 year period of analysis, structured searches were conducted for all articles that had the term 'integrated reporting' in their title, keywords (where available) and/or the abstract. In total 65 journal articles ${ }^{1}$ met these criteria, so were identified as addressing the IR idea. For each journal that published one or more IR-related article(s) over the period, Table 1 shows the number of articles identified per journal per year.

Table 1 - Distribution of Integrated Reporting accounting research over the six-year period 2012 to 2017

\begin{tabular}{|c|c|c|c|c|c|c|c|c|}
\hline & journals & 2012 & 2013 & 2014 & 2015 & 2016 & 2017 & TOT \\
\hline$A b$ & Abacus & & & & & & 1 & 1 \\
\hline$A B R$ & Accounting and Business Research & & & & & 1 & 1 & 2 \\
\hline $\mathrm{AF}$ & Accounting Forum & & & & & 1 & 1 & 2 \\
\hline
\end{tabular}

\footnotetext{
${ }^{1}$ We included all journal articles except calls for papers, book reviews, teaching cases, short commentaries, poems or editorial communications.
} 


\begin{tabular}{|c|c|c|c|c|c|c|c|c|}
\hline & journals & 2012 & 2013 & 2014 & 2015 & 2016 & 2017 & TOT \\
\hline $\mathrm{AH}$ & Accounting Horizons & 1 & & & & & & 1 \\
\hline AAAJ & Accounting, Auditing \& Accountability Journal & & & 6 & 2 & & 1 & 9 \\
\hline AOS & Accounting, Organizations and Society & & & & & & 1 & 1 \\
\hline AAR & Australian Accounting Review & & & & & & 2 & 2 \\
\hline BRIA & Behavioral Research in Accounting & & & & 1 & & & 1 \\
\hline BAR & British Accounting Review & & 1 & & 1 & 1 & 1 & 4 \\
\hline CPA & Critical Perspectives on Accounting & & & & 4 & 2 & 1 & 7 \\
\hline EAR & European Accounting Review & & & & & & 1 & 1 \\
\hline IJDAR & International Journal of Digital Accounting Research & 1 & & & & & & 1 \\
\hline IAE & Issues in Accounting Education & & & & 1 & & & 1 \\
\hline JAPP & Journal of Accounting and Public Policy & & & & 1 & & 1 & 2 \\
\hline JIFMA & Journal of International Financial Management and Accounting & & & 1 & & & 1 & 2 \\
\hline MAJ & Managerial Auditing Journal & & & & 1 & 2 & 1 & 4 \\
\hline MEDAR & Meditari Accountancy Research & & & & 3 & & 12 & 15 \\
\hline QRAM & Qualitative Research in Accounting and Management & & & & & 1 & & 1 \\
\hline RQFA & Review of Quantitative Finance and Accounting & & & & & 1 & & 1 \\
\hline SEAJ & Social and Environmental Accountability Journal & & & & 1 & & & 1 \\
\hline \multirow[t]{2}{*}{ SAMPJ } & Sustainability Accounting, Management and Policy Journal & & & 1 & 4 & 1 & & 6 \\
\hline & Total number of articles & 2 & 1 & 8 & 19 & 10 & 25 & 65 \\
\hline
\end{tabular}

The reason for this filtering methodology is conceptually similar to the method used in Unerman and O'Dwyer (2010) and Dumay et al. (2016). Authors of journal articles are, in effect, expected to flag up the main focus of their paper in its title, key words and abstract so any articles whose authors considered their article to be focusing on addressing IR should have this reflected in their title, keywords and/or abstract. However, it is possible that for some articles the key focus might not be reflected in the title, keywords or abstract. This is a limitation of the paper. Nonetheless, given that the whole population of articles has been analyzed, if the main focus of a small number of articles was not reflected in their title, keywords or abstract, this theoretical potential for an error should not materially affect the overall picture portrayed by the results of the study (Unerman and O'Dwyer, 2010).

Another important limitation is that this review is restricted to one communication channel, namely academic journal articles. Previous research has noted that this channel is not always appropriate for capturing all academic research (Dumay et al., 2016). Practitioners' journals, research monographs, books and conference proceedings are all channels that scholars utilize to engage with a wider audience. These outlets provide insights to help develop accounting research and practice related to IR, and their outputs should be considered in any future studies of this type.

All 65 articles identified through the above processes were downloaded and a systematic analysis of these articles was carried out to identify the purposes and the key themes of each article. A theme table was prepared for each article which summarized these themes though recording the article's: keywords, research method, nature of the study, focus of the research, theory used (where available), jurisdiction, research design, and locus of the article's inquiry in terms of macro-, meso- or micro-level analysis. At the macro-level, researchers are interested in exploring social structures and institutions. In the context of 
$I R$, macro-level research could include the study of the forms of governance in the context of accounting standard setting. At the meso-level, researchers investigate larger groups and the interaction between groups. Within the IR field, for example, this level of inquiry could comprise studies into how the accounting profession is involved in the formation, development and evolution of IR practices or the extent to which organizations embrace IR ideas. Finally, at the micro-level researchers examine detailed levels of interaction and are interested in how the perceptions of single individuals or small groups are influenced by the social context. An example of micro-level research could include the study of one-to-one interactions between organizational actors in implementing or understanding the IR idea.

The theme table was useful for gaining a sense of the different types of issues and problems being investigated and discussed in the IR accounting academic literature, how often these problems were explored, from what perspective and by what journals. Once the theme table was constructed, core categories related to the concept of the 'idea journey' (PerrySmith and Mannucci, 2017) were identified and individual themes were grouped under these categories. The data analysis was an iterative process with the inquiry moving between the information found in the literature reviewed and the theoretical framing adopted, until a conceptual structure of the field was formed. Even after the first classification was finalized, we continued searching for newly published relevant articles and updated the data set where necessary. This allowed the grouping of IR research idea into the five broad sequential phases of the journey:

1. idea generation: includes research analysing the process of shaping the IR idea from the grouping and integration of many sources of knowledge;

2. idea elaboration: involves studies that investigate the processes whereby the IR idea was assessed and developed (this includes, for example, research that analyzes the ways in which the IR idea was presented to the community, discussed, tested and fedback);

3. idea championing: includes research that explores the potential for the IR idea to obtain influence and legitimacy at the level of the organization and/or the field (this comprises, for example, research that analyzes how the business case for IR was formulated and how approval was sought);

4. idea production: involves studies that investigate the wider processes whereby the conceptual idea of IR is turned into something tangible (this includes, for instance, research that analyzes the specifics that help organizations convert the ideas of the IIRC into practice);

5. idea impact: includes research that explores the how and to what extent the IR idea comes to be accepted and recognized in the field (this includes, for instance, research that examines how the idea overcomes resistant from field members or impacts development of the field).

The data for each of these broad categories are presented and analyzed in the next section of this paper where the IR idea journey is presented and critically discussed. To help the discussion, the results are presented according to the sequential structure of the theoretical framing. 


\section{The journey of the Integrated Reporting idea}

Table 1 shows that IR has been the subject of a growing volume and scope of research studies. The volume of publications has increased considerably over time: from two journal articles published in 2012 to 24 in 2017. Research dealing with issues related to IR was not evenly distributed across the journals reviewed, with a large proportion of articles concentrated in a small number of journals: five journals (Accounting, Auditing \& Accountability Journal; Meditari Accountancy Research; Critical Perspectives on Accounting; Sustainability Accounting, Management and Policy Journal; and the British Accounting Review) accounted for almost $70 \%$ of the articles.

Table 2 presents a schematic illustration of the articles that have been published, structured around the five phases of the idea journey framework which they primarily address. Each article in Table 2 has been categorized into one of the idea journey phases according to our interpretation of its primary purpose, as denoted by dark grey shading in the table. However, as these articles were not produced with the intention of fitting into the stages of the idea journey framework, most studies provide insights that span more than one stage of the idea journey framework. We have therefore classified each article according to our interpretation and understanding of the stage of the IR idea journey that its insights primarily inform. We also show in lighter shading other stages of the IR idea journey that each paper covers but less fully than the main stage it covers. Each article's locus of inquiry (macro, meso or micro) is noted within the cell shaded for its primary purpose. The following sub-sections synthesize the key insights produced by the body of literature we have classified as relevant to each phase in the IR idea journey (idea generation, idea elaboration, idea championing, idea production and idea impact).

Table 2 - Integrated Reporting accounting research published between 2012 and 2017, classified by phase

\begin{tabular}{|c|c|c|c|c|c|}
\hline \multirow{2}{*}{ Journal Articles } & \multicolumn{5}{|c|}{ Phases of the idea journey framework } \\
\hline & generation & elaboration & championing & production & impact \\
\hline Gonzalbez and Rodriguez (2012) & macro & & & & \\
\hline Cheng et al. (2014) & macro & & & & \\
\hline Flower (2015) & macro & & & & \\
\hline Thomson (2015) & macro & & & & \\
\hline Adams (2015) & macro & & & & \\
\hline Reuter and Messner (2015) & macro & & & 8 & 0 \\
\hline Vinnari and Dillard (2016) & macro & & & & \\
\hline Rowbottom and Locke (2016) & macro & & & & \\
\hline Beattie and Smith (2013) & & macro & & & \\
\hline de Villiers et al. (2014) & & macro & & & \\
\hline Brown and Dillard (2014) & & macro & & & \\
\hline Atkins et al. (2015a) & & macro & & & \\
\hline Atkins et al. (2015b) & & macro & & & \\
\hline
\end{tabular}




\begin{tabular}{|c|c|c|c|c|c|}
\hline \multirow{2}{*}{ Journal Articles } & \multicolumn{5}{|c|}{ Phases of the idea journey framework } \\
\hline & generation & elaboration & championing & production & impact \\
\hline Simnett and Huggins (2015) & & macro & & & \\
\hline Tweedie and Martinov-Bennie (2015) & & macro & & & \\
\hline Haller and van Staden (2014) & & meso & & & \\
\hline Coulson et al. (2015) & & meso & & & \\
\hline Rambaud and Richard (2015) & & meso & & & \\
\hline Dumay et al. (2017) & & meso & & & \\
\hline Chaidali and Jones (2017) & & meso & & & \\
\hline Maroun (2017) & & meso & & & \\
\hline Ballou et al. (2012) & & & macro & & \\
\hline Owen (2013) & & & macro & & \\
\hline van Bommel (2014) & & & macro & & \\
\hline Steyn (2014) & & & macro & & \\
\hline Bernardi and Stark $(2018)^{2}$ & & & macro & & \\
\hline de Villiers and Sharma (2016) & & & macro & & \\
\hline Baboukardos and Rimmel (2016) & & & macro & & \\
\hline Ahmed Haji and Anifowose (2016) & & & macro & & \\
\hline Dumay et al. (2016) & & & macro & & \\
\hline Humphrey et al. (2017) & & & macro & & \\
\hline Stubbs and Higgins (2014) & & & & macro & \\
\hline Cohen et al. (2015) & & & & macro & \\
\hline Setia et al. (2015) & & & & macro & \\
\hline Haji and Anifowose (2016) & & & & macro & \\
\hline Gunarathne and Senaratne (2017) & & & & macro & \\
\hline Venter et al. (2017) & & & & macro & \\
\hline Roslender and Nielsen (2017) & & & & macro & \\
\hline Reimsbach et al. (2017) & & & & macro & \\
\hline Melloni et al. (2017) & & & & macro & \\
\hline García-Sánchez and Noguera-Gámez (2017) & & & & macro & \\
\hline du Toit (2017) & & & & macro & \\
\hline de Villiers et al. (2017a) & & & & macro & \\
\hline Higgins et al. (2014) & & & & meso & \\
\hline Stent and Dowler (2015) & & & & meso & \\
\hline Adams et al. (2016) & & & & meso & \\
\hline Haji and Hossain (2016) & & & & meso & \\
\hline Oliver et al. (2016) & & & & meso & \\
\hline Adams (2017) & & & & meso & \\
\hline Lodhia and Stone (2017) & & & & meso & \\
\hline
\end{tabular}

2 This paper was published in 2016 as article "In Press, Corrected Proof" (http://dx.doi.org/10.1016/ j.bar.2016.10.001) yet included in a regular issue only in 2018. 


\begin{tabular}{|c|c|c|c|c|c|}
\hline \multirow{2}{*}{ Journal Articles } & \multicolumn{5}{|c|}{ Phases of the idea journey framework } \\
\hline & generation & elaboration & championing & production & impact \\
\hline Del Baldo (2017) & & & & meso & \\
\hline du Toit et al. (2017) & & & & meso & \\
\hline Dumay and Dai (2017) & & & & meso & \\
\hline Guthrie et al. (2017) & & & & meso & \\
\hline Lai et al. (2017) & & & & meso & \\
\hline Macias and Farfan-Lievano (2017) & & & & meso & \\
\hline McNally et al. (2017) & & & & meso & \\
\hline Segal et al. (2017) & & & & meso & \\
\hline Silvestri et al. (2017) & & & & meso & \\
\hline Haji (2015) & & & & meso & \\
\hline Atkins and Maroun (2015) & & & & & macro \\
\hline Zhou et al. (2017) & & & & & macro \\
\hline Barth et al. (2017) & & & & & macro \\
\hline Lee and Yeo (2016) & & & & & macro \\
\hline Robertson and Samy (2015) & & & & & meso \\
\hline Phase most closely cov & $\square$ & & & & \\
\hline Phases more periphera & rticle & & & & \\
\hline
\end{tabular}

\subsection{Idea generation phase}

This phase covers the processes of generating the IR idea. It includes eight articles that provided insights into the politics of standard-setting, focusing on both the processes and the various bodies that contributed to shaping the emergence of the IR framework. This literature highlighted that for the IIRC'S IR Framework to implement radical changes in business models, the standard-setting process needed to stimulate pluralistic engagement around the nature and role of accounting measures and how they might better serve the needs of a broad range of members of society. A number of these studies set out and discussed the history of the IIRC, claiming that the approach to IR had been 'captured' by preparers and the accountancy profession, resulting in movement away from its original objectives (Flower, 2015; Thomson, 2015; Adams, 2015). These studies revealed important tensions in the network of bodies engaged in developing and promoting IR (Rowbottom and Locke, 2016), and analyzed active lobbying behaviour toward the IIRC - with preparers engaging more heavily than users and emphasising investor needs and shareholder value creation (Reuter and Messner, 2015). This literature also provided insights on key issues that were debated in relation to the IIRC's consultation processes that sought views from stakeholders (Cheng et al., 2014; Gonzalbez and Rodriguez, 2012), arguing that a more democratic form of governance in the process for developing the IR framework would better serve progressive social programmes (Vinnari and Dillard, 2016). 


\subsection{Idea elaboration phase}

This phase is concerned with the process of assessing and further developing the potential of the IR idea, and comprises 13 articles. This literature highlighted the numerous theoretical and empirical challenges associated with understanding and developing IR ideas. Drawing upon academic analysis and insights provided in the early stages of IR academic literature, De Villiers et al. (2014) raised awareness of the field's potential in a systematic fashion. The key insights produced by accounting research relevant to this phase emerged from two avenues of investigation: the effectiveness of IR and the potential for IR to bring about organizational change.

To increase the effectiveness of $I R$, some studies suggested the development of new approaches. Simnett and Huggins (2015), for instance, argued that the market-based benefits of adopting the framework must be demonstrated for IR to develop traction and international acceptance, and noted that the development of a sophisticated business case informed by research would be critical to the uptake of the framework. Coulson et al. (2015), instead, illuminated the potential tensions between multiple capitals and provided normative insights into the need for engagement on the philosophies of integrated thinking and symbolism of capital. Trust (or the lack of it) can also play an important role in the promotion of IR ideas. Chaidali and Jones (2017) conceived IR as a "trust-building process" and considered the stages in which the IIRC disseminated its proposals to build trust in the IR initiative. Other studies advanced examples of alternative reporting models, such as the value-added statement (Haller and van Staden, 2014), the 'Triple Depreciation Line' model (Rambaud and Richard, 2015), and an assurance framework for integrated reporting (Maroun, 2017). A significant aspect of these accounting studies is the general proposition that, to increase its effectiveness, IR should include information of the monetary effects of different types of capital in an ecological accounting context.

Research within this phase also provided insights into the potential of IR to bring about organizational change. Tweedie and Martinov-Bennie (2015), for example, showed that the IR idea has moved away from the key tenets of prior social and environmental reporting frameworks. Even though their article may appear to cover similar ground to Flower (2015), Thomson (2015) and Adams (2015) (and there are, indeed, overlaps), these other papers mostly commented on the process whereby the IIRC finalised the IR framework, whereas Tweedie and Martinov-Bennie (2015) mostly dealt with the IR framework moving forward and thus contributed more to elaborating the IR idea rather than to critiquing the generation of the IR idea. Consequently, Tweedie and Martinov-Bennie (2015) argued that for IR to make a difference in organizations and broader society, it should contribute to a broader social transformation in corporations and financial markets, rather than becoming another reporting framework. Brown and Dillard (2014) similarly elaborated rather than critiqued the generation of IR, when they critically assessed the value of $I R$ as a sustainability change initiative going forward. They argued that the IIRC's proposals ignored and obscured other possible pathways that would be based on stakeholder accountability and critical framings in closing down around business case framings of social and environmental reporting and sustainability. 
Other researchers examined both the enablers and barriers to implementing IR (Dumay et al., 2017) and maintained that the IR Framework's business model concept offers a powerful overarching idea within which to refocus the accounting for non-financial capital debate (Beattie and Smith, 2013). For example, Atkins et al. (2015a) suggested that IR is unlikely to change how large companies do business in order to address major societal and environmental problems in the short-term. However, rendering visible the costs of these problems through forms of monetization could encourage integrated thinking and sustainable business models. Other research focused on how IR practices could become institutionalized though practices of integrated private reporting (Atkins et al., 2015b)

\subsection{Idea championing phase}

This phase involves promoting the IR idea through obtaining support to push the idea forward. Research in this phase includes 10 articles that provided theoretical and empirical insights into the various ways in which the IR idea sought to gain authority and traction.

Accounting scholars have highlighted that for IR ideas to progress successfully, the multiplicity of views on this form of disclosure need to be reconciled to make it acceptable to, and legitimate for, a broad audience. Otherwise, IR ideas risk becoming captured by investors and accountants, leading to local private arrangements rather than ideas acknowledged and accepted by the entire field (van Bommel, 2014). The IIRC's attempts to institutionalize IR as a practice is a good example. The study by Humphrey et al., (2017) demonstrated how much the IIRC's prospects for success in reconfiguring the corporate reporting field depended on its ability to reconfigure the mainstream investment field. By examining emergent IR practice (Dumay et al., 2016), the literature showed that it was unlikely that IR would be able to provide all the information currently reported in GRI-type reports (de Villiers and Sharma, 2016). This strand of research critically analyzed the case that the adoption of an integrated approach improves the usefulness of financial reporting for investors (Bernardi and Stark, 2016; Baboukardos and Rimmel, 2016).

While the intended audience of the report in the framework are the providers of financial capital, managers are more motivated by its legitimizing potential in compiling an integrated report than in satisfying investor needs (Ahmed Haji and Anifowose, 2016; Steyn, 2014). Lastly, some empirical research investigated the relationships between the accounting profession and IR ideas examining the influence IR could have on the education and training of accountants (Owen, 2013), finding that when accounting professionals are involved, they have an important role in integrating non-financial reporting with traditional financial reporting (Ballou et al., 2012).

\subsection{Idea production phase}

This phase is the process of turning an idea into something discernible, such as a product or a service. We identified 29 articles that explored how IR ideas are understood and ultimately operationalized. There are several insights that emerged from this body of literature. What is particularly significant is its focus on the dynamics of adoption and implementation of IR. We have grouped these into 3 areas: the role of IR in shaping 
organizations' internal processes; the areas and directions of IR development; and the influence of IR on stakeholders' information processing.

A key insight is that IR's development strongly depends on its (yet to be demonstrated) capacity to affect organizations' internal processes. One stream of research examined the roles of motivation and incentives systems in the production of IR. McNally et al. (2017), for example, found that preparers were unconvinced that integrated reports were taken seriously by investors. As a result, IR ideas were felt to be imposed on existing internal processes with the reporting guidelines used as mere disclosure checklists. García-Sánchez and Noguera-Gámez (2017) showed that firms' incentives were the main determinants of voluntary adoption of IR. Adopting a different perspective, Stubbs and Higgins (2014) studied the potential of IR to foster transitions to more sustainable business practices. They found that while organizations that produced some form of integrated report were changing their processes and structures, the nature of this change was incremental rather than radical and transformative. Finally, Adams (2017) examined the complex interrelationships which influenced the ability of organizations to create value for their providers of finance and other stakeholders, finding that the IR framework influenced cognitive frames, resulting in awareness of the importance of environmental, social and governance issues together with a broader view of value creation.

Empirical research investigating specific aspects of IR practice provided insights into how integrated thinking is considered and applied within organizations (Oliver et al., 2016; Venter et al., 2017). Accounting scholars have highlighted how specific principles of IR are implemented by preparers (du Toit, 2017; Lai et al., 2017; Silvestri et al., 2017). Setia et al. (2015) analyzed the effect of the introduction of IR regulation while other studies investigated the role and the effectiveness of internal auditing in the context of integrated reports (Haji, 2015; Haji and Anifowose, 2016). As more studies undertook empirical research, de Villiers et al. (2017a) found that not much of this literature investigated the economic effects associated with IR. By providing a review of the capital markets studies, their article provides an empirical understanding of measurement issues in IR research.

Another stream of literature within this phase provided insights into how IR was developing. Adams et al. (2016) explored the evolution of business reporting toward more integrated approaches in four large multinational organizations. Their results indicated that organizations were starting to think about their social investment activities in terms of value creation in different ways, and were linking these activities to strategy. Higgins et al. (2014), by contrast, provided in-depth insights into the processes of institutionalization of IR by examining the early adopters of IR practice. In terms of accountability and stewardship for the broad base of capitals, Haji and Hossain (2016) analyzed how companies reported and integrated multiple capitals in various organizational reporting channels. Drawing on the intellectual capital reporting experience in Denmark, Roslender and Nielsen (2017) reflected on the major obstacles that confront the advocates of narrative disclosure practice. Finally, Lodhia and Stone (2017) explored the role of Internet-based communication technologies as enabler of the IR process.

Recent empirical studies examined the key issues in the development of IR in various organizational settings. Del Baldo (2017), for instance, discussed the critical aspects relative 
to the usability of IR for small and medium-sized enterprises. Guthrie et al. (2017) investigated the internal mechanisms of change that can lead organizations adopting IR to pursue integrated thinking in the context of public service organizations. Finally, Gunarathne and Senaratne (2017) explored how and why IR is spreading in emerging markets, focusing on Sri Lanka.

There have also been articles providing insights into how IR influences investors' information processing (Cohen et al., 2015; du Toit et al., 2017; Macias and Farfan-Lievano, 2017; Reimsbach et al., 2017) and the role of IR for control, risk and impression management policies (Melloni et al., 2017; Segal et al., 2017).

\subsection{Idea impact phase}

The final phase concerns discussion of whether, or to what extent, IR is acknowledged and accepted in the field. This phase is covered by five articles that empirically investigate the benefits of IR for both financial markets and society at large. The literature relevant to the impact phase provided insights into the attitude of reporting organizations and the role of senior managers in acknowledging the IR idea. This literature also offered empirical insights into relationships between the quality of IRs, the financial consequences of IR, and its effect on analyst forecast accuracy.

Atkins and Maroun (2015), for example, investigated the reactions of the South African institutional investment community to the first sets of IRs being prepared by companies listed on the Johannesburg Securities Exchange. While revealing several ways in which IR could be improved, the findings indicated the beginning of a broader reporting attitude by organizations and an integrated approach to conceiving business activities. Robertson and Samy (2015) analyzed factors that either helped or hindered diffusion of the IR idea. Their study suggested that senior managers were supportive of IR and organizations were integrating their reporting along the lines suggested by the IIRC framework. Barth et al. (2017) focused on investors and markets. Their article empirically evaluated the extent to which the IR idea fulfilled its aims to improve the quality of information available to investors and create value over time by promoting integrated thinking. By studying the association between IR quality and firm value, the article found that better quality IR was associated with better financial outcomes for firms, measured in several different ways. In a similar vein, Lee and Yeo (2016) found a positive association between IR disclosures and firm valuation. Finally, Zhou et al. (2017) provided evidence that IRs with a higher level of alignment with the IIRC's IR Framework improved the quality of information for reporting companies, as evidenced by better analyst forecast accuracy.

In summary, research insights into the five phases of the IR journey taken together provide evidence that, at its core, the IR literature is co-evolving with the challenges and opportunities posed by the increasingly established practice of IR at various levels of analysis. A key finding that emerges from the theoretically informed analysis of the IR academic literature is that research has not yet covered the entire IR journey. The highest proportion of articles provided insights in the generation and production phases, while there is relatively little research into the final phase of the impact of the IR idea. Without considering the journey in its entirety, it is difficult to understand the effects of IR and the 
extent to which practices and tactics at different stages of the IR journey may have contributed to changing the field (Perry-Smith and Mannucci, 2017). Another important finding of the above analysis is that the locus of research covered by the current IR literature is situated at macro- and meso-levels. This reveals an important gap for future research to explore, at a more detailed level, interactions between single individuals or small groups in implementing and/or understanding the IR idea. The findings of the papers published in this $A A A J$ special issue go some way to filling these gaps through a range of indepth case studies that are summarized in the next section.

\section{Insights from contemporary idea impact phase IR research}

The papers in this $A A A J$ special issue provide a range of micro-level analysis of IR practices based on the IIRC framework at the idea impact phase of IR's journey. This research comprises five case studies of organizations from a variety of jurisdictions, with case insights analyzed within the sociological, critical and interpretative traditions. Collectively, the cases underline the challenges and opportunities faced by individuals and organizations in the processes of understanding and employing IR ideas, and the extent to which new ideas are acknowledged and embraced.

Maroun and Mcnally's (2018) stated aim is to examine the potential of accounting and accountability practices to bring about transformational change. To achieve this aim, the paper employs a case study of a medium-sized organization in South Africa focusing on the internal mechanisms of change at individual and organizational levels triggered by the decision to adopt the IIRC's framework. Drawing on an organizational change theory and logics of resistance, the study shows how variations in individual preparers' understanding and application of IR principles influence changes to reporting systems. While the paper finds that financial considerations are still paramount, the study challenges the introduction of new accounting systems as a mere response to hegemonic pressures.

The paper draws on a series of in-depth interviews with employees involved both in the preparation of the IR and the reporting infrastructure, along with documents provided by the case study organization. Maroun and Mcnally (2018) point to different levels of resistance to the introduction of $I R$ and integrated thinking that can undermine its change potential (i.e. lack of understanding of the potential of IR; different interpretations and application of the new reporting framework by individuals within the organization; overreliance on rules or guidelines; compliance-based approach to reporting). The adoption of IR expands the scope of the conventional accounting system, thus promoting broader management control and a more integrated conception of value. Maroun and Mcnally (2018) found that while resistance may not facilitate change, the new accounting system is driving higher levels of proactivity among individual employees. Its functioning has urged them to work collaboratively toward common objectives, thus promoting a shared and therefore more impactful vision of the IR idea (Perry-Smith and Mannucci, 2017).

Gibassier et al. (2018) investigate the processes whereby organizations comprehend and assimilate the management innovation associated with IR. More specifically, Gibassier et al. (2018) provide insights into how the adoption of the IR innovation unfolded by studying 
organizational actors in their real-life environment. Drawing on a seven-year longitudinal ethnographic study based on semi-structured interviews, observations, and documentary evidence, Gibassier et al. (2018) analyze a multinational consumer goods organization's IR adoption process from its decision to become an IIRC pilot organization through to the publication of its first integrated report. Their findings reveal that individuals inside the company embraced the "mythical" dimension of IR, residing in the aspirational and imaginary features. As a result, organizational actors reflected on the nature of IR and developed collective conceptualizations and re-conceptualizations of the IR process. Throughout the IR journey, individuals connected these conceptions to the foundational socio-economic vision of the company, and the mythical dimension of IR facilitated understanding of the new idea by promoting the creation and recognition of a common language, thus the development of heuristics and shared meaning (Perry-Smith and Mannucci, 2017). The paper highlights how inconsistencies between the IR concept and its translation by the IIRC, along with managers' faith in the project, allowed the organization to challenge and debate elements of the IIRC's approach and ultimately to (re)conceptualize and implement its own version of an IR. In doing so, it contributes to further exploring the imaginary function of management innovations. A significant implication of Gibassier et al.'s (2018) findings is the importance for an organization's foundational myth to be aligned with the mythical dimension of the management innovation. In summary, if organizations wish to realize the full potential of IR they need to make sure its aspirational features are aligned with the company's foundational (or current) socio-economic vision.

Lai et al. (2018) investigate how the adoption of IR could broaden the scope of stakeholder engagement and lead to new models and methodologies that meet broader demands of accountability. More specifically, their paper explores the extent to which the narrative turn solicited by the adoption of IR enhances accountability by facilitating dialogue with various stakeholders. Framed through research on narrative accountability, Lai et al. (2018) investigate the function that the narrative mode of cognition serves, in helping social actors make sense of their lives, particularly by shaping chaotic, unexpected, or anomalous events into a coherent story. The paper finds that such a narrative mode of cognition influences the patterns of accountability associated with IR and facilitates dialogue between preparers and users.

The paper empirically analyzes the experience of IR preparers during the process of IR construction, within a large organization in Italy. Drawing on several in-depth interviews with staff involved in the implementation and review of IR, Lai et al. (2018) find that the implementation of IR has offered directors, managers, and employees an opportunity to discuss how to communicate with stakeholders, and reflect on how to align their disclosure with stakeholders' increasing information needs. Such reasoning processes drove preparers to craft their IR in a way that renders contingent events comprehensible. This implied forging of a value creation story, making sure the information provided covers multiple areas and cultures of the company and is comprehensible beyond the boundaries of the organization, thus gathering recognition and support from stakeholders in the field (PerrySmith and Mannucci, 2017). Despite findings showing that IR can produce socializing effects for a range of stakeholders (i.e., employees, consumers, strategic partners, academics and students), the study also reveals that investors and the other financial stakeholders remain key and continue to represent the primary recipients of IR. As a result, the paper raises 
concerns regarding how IR can be the driving force towards more holistic forms of accountability.

Vesty et al. (2018) examine a multiplicity of views on IR and show how legitimacy struggles are resolved in practice around complex accounting technologies in heterogeneous environments. The empirical analysis draws on a personal narrative expressed by the Chairman of an IR pilot organization in Australia. This unique access offers insights into how an individual actor who is at the heart of decision-making reconciles organizational experimentation with the IIRC's IR Framework. In doing so, the paper provides a micro-level analysis of the impact of IR practice, offering a critical discussion into how IR plays out in practical, everyday modes of organizing.

To illuminate the multiple logics of valuation at work around IR, and the difficulties involved in bringing them together in a state of legitimacy, the paper adopts Boltanski and Thévenot's $(1999 ; 2006)$ 'sociology of worth' framework. This theoretical underpinning allowed Vesty et al. (2018) to frame IR as a new test and compromise for corporate reporting and to examine how the IR process helped the case study organizations bring to the forefront discussions on the best way to express their value proposition. As new ideas are characterized by high uncertainty and questionable legitimacy, the paper shows how the characteristics and the structural position of the Chairman can act as indications to others in the organisation about whether to support implementation of the IR idea (Perry-Smith and Mannucci, 2017). The research also adds key insights to the IR accounting literature more broadly. For example, it offers more nuanced views of the micro-level justifications at play when individual actors attempt to align themselves with multiple states of worth to legitimately join the IR debate. Additionally, it provides an account of the lived experience of being an IR pilot organization and the compromises made to achieve a 'common good'. It also shows how the reporting decisions justified by the Chairman were very much driven by senior management, who were keen to ensure that their strategies were reflected in operational decisions.

Finally, von Alberti-Alhtaybat and Al-Htaybat (2018) investigate the link between integrated thinking and IR in a large organization. Framed though the lenses of Bourdieu's $(1977,2010)$ 'theory of practice', the paper illustrates the underlying mechanisms whereby the case study organization came to be an 'integrated thinker'. The study highlights key roles of individuals (i.e. senior management) and organizational dispositions and associations with the field (i.e. the need to deal with uncertainty and disruption) in the emergence of an integrated thinking approach. The paper finds this developed three decades prior to the concept being formally introduced in the IIRC'S IR framework. The paper highlights how the tie between key individuals and distinctive organizational characters provides the structural opportunity for successful impact of IR, in that it helps keep the organization "in line" with the principles of the new idea (Perry-Smith and Mannucci, 2017). Alberti-Alhtaybat and AlHtaybat (2018) also find that in their case study organization integrated thinking and IR are strongly linked, with the former being an originator of the latter. These findings support Gibassier et al.'s (2018) conclusions suggesting that for IR to be an effective mechanism of enhanced accountability, all organizational members need to embrace an integrated thinking approach and structures. 
The summaries of the papers included in this $A A A J$ special issue provide an indication of the insights these academic studies can offer to the understanding of several key themes surrounding the impact of the IR idea. Three papers investigate the IR idea impact by examining the adoption process. Maroun and Mcnally (2018) focus on individual preparers and elucidate how changes to reporting systems link to the impact of a new idea by promoting collaboration and shared understanding. Framed though the lenses of 'rational myth', Gibassier et al. (2018) demonstrate the key role of motivating rituals in facilitating the impact of a new idea. Whereas Lai et al. (2018) find that the structure of cognition employed by IR preparers promotes acceptance and recognition of the new idea in the field by facilitating dialogue within IR preparers and between IR preparers and IR users. The remaining two papers explore the IR idea impact by investigating links between IR and senior management thinking and decision-making. These studies offer insights into cues used by decision makers to determine whether they will support implementation of the IR idea. The papers highlight the roles and structural position of senior management in implementation of IR (von Alberti-Alhtaybat and Al-Htaybat, 2018; Vesty et al., 2018).

Apart from being located in the idea impact phase of the IR idea journey, the five papers in this special issue also contribute to the IR literature by providing insights at the micro-level locus of research. Maroun and Mcnally (2018), for example, examine the behaviour of preparers within an organization, providing evidence on how the requirement or recommendation to produce an integrated report is being interpreted and applied by single individuals. Gibassier et al. (2018) examine how individuals inside a large organization developed collective conceptualizations and re-conceptualizations of IR. In a similar vein, Lai et al. (2018) analyze how modes of cognition of the staff involved in IR implementation and reviews can influence patterns of accountability enabled by IR. From a different perspective, Vesty et al. (2018) investigate how the Chairman of an IR pilot organization engages with IR to better understand senior management perceptions of IR, and how IR was put to the test within the organization. Lastly, von Alberti-Alhtaybat and Al-Htaybat (2018) examine how a senior manager of a large organization commits to integrated thinking and manages it from the top.

Adding to these significant contributions, future research might develop further in-depth theoretical and empirical knowledge of the IR idea. Figure 1 provides a broad summary of the IR journey and locates the prior and contemporary IR literature within the appropriate idea journey phases. Note that where the reference to some papers is placed across the boundary between two phases, this is intentional and illustrates that the paper contributes in more than one phase of the idea journey. The positioning of the references on boundaries also indicates their relative contribution to the idea journey phases on either side of the boundary. The new papers published in this AAAJ special issue are highlighted in bold. Their position in Figure 1 demonstrates that these papers are at the forefront of contemporary IR research.

The next section, draws conclusions from this the paper and suggests several research areas and opportunities that still warrant academic investigation. 


\section{Figure 1 - The dynamics of the Integrated Reporting idea journey: locating the IR literature}

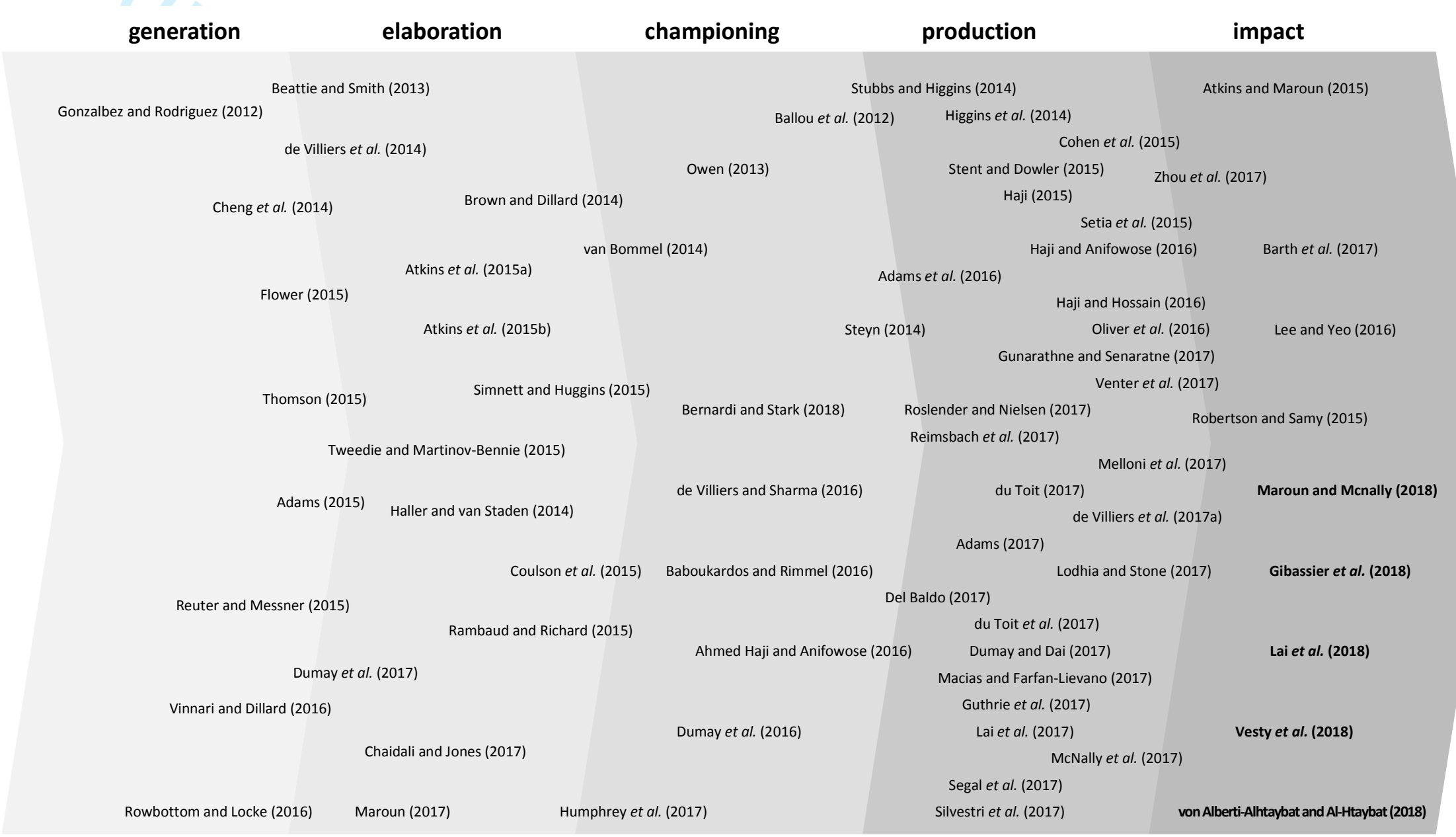

Note: Papers in bold are those included in this AAAJ special issue; Papers that cross borders are those that provide insights spanning more than one phase. 


\section{Conclusions and research agenda}

The aim of this paper has been to analyze the overall IR journey of the IIRC's version of IR, as revealed through insights within the academic literature, to highlight challenges, successes, strengths and weaknesses of IR and identify gaps. To fulfil this aim, the paper used the idea journey theoretical framework (Perry-Smith and Mannucci, 2017) to classify and structure insights from the literature. The framework set out five main phases to structure analysis of the development and implementation of the IR idea: idea generation; idea elaboration; idea championing; idea production; and idea impact.

As can be seen from the analysis in this paper, there are a rich variety of insights across most phases of the IR journey. We found that the main focus of the literature was placed on the production of IR (mainly within large organizations operating in developed Englishspeaking countries) with limited, but growing attention devoted to the impact phase of the IR journey. Given that IR is at an early stage of implementation, a limited number of studies at the impact phase could have been anticipated. However, if we want to understand the extent to which IR has contributed to changing the field, advances in IR practices offer an opportunity to research complex micro dynamics and interdependencies underlying accounting in the impact phase of the journey.

This study contributes to the IR research in two ways. First, this paper extends IR accounting research by reconciling insights from an understandably fragmented emerging literature, by locating the prior literature in the five phases through which IR has moved. This built on the work of innovation and creativity scholars (Perry-Smith and Mannucci, 2017) who highlighted the importance of an explicit distinction among phases for considering the entire journey of a new idea. By following the IR idea from its formation to its dissemination and impact, this paper provides a multi-dimensional perspective on IR - highlighting the dynamics and interrelationships in the literature. Second, this study identified gaps regarding the stages of the IR idea journey that have not been covered by the extant academic literature. Given the increasing range of IR practices and policies, there is considerable scope for novel approaches that provide a deeper empirical and theoretical understanding of IR ideas 'in action'. As a result, our paper demonstrates how the idea journey framework can be used to shape and add coherence to the overall body of IR research.

In conclusion, the idea journey framework has provided an overarching logic for creating a new understanding of the IR literature, and has helped identify gaps. Some of these gaps have been filled by the papers published in this $A A A J$ special issue, but there are several avenues for future research that can be further explored to investigate the impact of IR ideas. Among these are following four areas:

First, as stakeholder groups are increasingly intended to become involved in the construction and use of IR (IIRC, 2016; 2017), future research could critically examine the role of IR ideas in mediating the relationships between organizations and stakeholders. One way to investigate the impact of IR could be developing new models and methodologies for 
understanding and/or implementing forms of integrated engagement. This would represent an area of research aimed at answering questions such as the following:

- How do organizations seek to provide integrated accounts of their performance and how do their stakeholder-user base engage with this accounting?

- How do distinctive stakeholder groups use IR ideas to construct their own accounts, and with what effect?

- What has led organizations and associated key stakeholders to embrace, exclude or ignore different forms of IR?

- How are NGOs, trade unions, social movements, and other stakeholder groups using organizations' IR?

- What strategies and framings are mobilized by stakeholders to enhance the impact of IR?

Second, a direction for further research would be to study the historical contingency of contemporary IR practices (Carnegie and Napier, 1996). Such research could provide an important contribution to understanding IR functionality, causality and evolution in a context where best practices have not yet consolidated into a norm. Comparative studies, for instance, may offer valuable opportunities to increase the understanding of the framings and structures that generate temporal and spatial differences among IR practices (or allow such differences). Comparative research is well-suited to addressing questions such as the following:

- What are the contingencies shaping different integrated thinking and reporting practices across firms, localities, industries and time periods?

- How do various institutional environments influence IR practices?

- What are the differences in attitudes and approaches towards integrated thinking between organizations and industries?

- What are the relationships between the guiding principles of IR (for example 'connectivity of information') and improved decision-making in different organizational contexts?

Third, Humphrey et al. (2017, p. 57) argued that the impact of IR "may ultimately depend upon which professional groupings and specialisms serve to influence the construction of any such 'integrated' reports". Consequently, for those researchers interested in addressing aspects of the accounting profession, future studies may examine the role of accountants in the adoption of IR ideas to answer questions such as the following:

- What decision processes have led organizations, stakeholders and professional groups to embrace, exclude or ignore different forms of IR?

- How and to what extent will IR ideas shape the professional space?

- Which professional groupings and specialisms will assist the development of integrated ideas and how?

- How and to what extent will the emergence of new integrated accounting processes, practices and expertise affect the accounting profession? 
Finally, academic investigations could contribute to developing a deeper understanding of how and why IR becomes associated with different arenas. This leads to questions about the agents that affected the nature and outcomes of contemporary IR practices such as the following:

- What factors explain the extent to which IR becomes accepted practice in certain contexts and at particular moments?

- How have integrated thinking and reporting come to be mobilized? What are their rationales and rationalizations?

- What strategies have been adopted to expand IR practices and how do they influence different institutional settings?

- How do integrated thinking and reporting begin?

- How does integrated thinking and reporting "in action" look and what are the internal rationales for adopting it that can potentially contradict public justifications?

The extent of the above questions requires the use of theories that enhance the robustness of the insights and understandings these enquiries will provide. This represents another stimulating research area aiming, for example, at:

- theorizing the conditions under which organizations engage in IR ideas;

- theorizing the process(es) through which IR and integrated thinking become established in organizational practices;

- developing decision-making frameworks aimed at assisting IR producers and users;

- critiquing current IR ideas aimed at promoting the development of newer and sounder practices; and

- developing new theoretical models seeking to provide novel understandings of the stakeholder engagement processes in the emerging field of IR.

While not exhausting the extent of the empirical and theoretical challenges that surround the impact of IR, the scope of the above research avenues and research questions show that academic IR research still has much potential. More focused examinations of the impact of IR ideas are likely to greatly add to our understanding of the development of IR practice. 


\section{References}

Adams, C. A. (2015), "The international integrated reporting council: A call to action", Critical Perspectives on Accounting, Vol. 27, pp. 23-28.

Adams, C. A. (2017), "Conceptualising the contemporary corporate value creation process", Accounting, Auditing and Accountability Journal, Vol. 30 No. 4, pp. 906-931.

Adams, C. A., Potter, B., Singh, P. J. and York, J. (2016), "Exploring the implications of integrated reporting for social investment (disclosures)", British Accounting Review, Vol. 48 No. 3, pp. 283-296.

Ahmed Haji, A. and Anifowose, M. (2016), "The trend of integrated reporting practice in South Africa: ceremonial or substantive?", Sustainability Accounting, Management and Policy Journal, Vol. 7 No. 2, pp. 190-224.

Atkins, J., Atkins, B. C., Thomson, I. and Maroun, W. (2015a), “"Good” news from nowhere: Imagining utopian sustainable accounting", Accounting, Auditing and Accountability Journal, Vol. 28 No. 5, pp. 651-670.

Atkins, J. F., Solomon, A., Norton, S. and Joseph, N. L. (2015b), "The emergence of integrated private reporting", Meditari Accountancy Research, Vol. 23 No. 1, pp. 2861.

Atkins, J. and Maroun, W. (2015), "Integrated reporting in South Africa in 2012: Perspectives from South African institutional investors", Meditari Accountancy Research, Vol. 23 No. 2, pp. 197-221.

Baboukardos, D. and Rimmel, G. (2016), "Value relevance of accounting information under an integrated reporting approach: A research note", Journal of Accounting and Public Policy, Vol. 35 No. 4, pp. 437-452.

Ballou, B., Casey, R. J., Grenier, J. H. and Heitger, D. L. (2012), "Exploring the Strategic Integration of Sustainability Initiatives: Opportunities for Accounting Research", Accounting Horizons, Vol. 26 No. 2, pp. 265-288.

Barth, M. E., Cahan, S. F., Chen, L. and Venter, E. R. (2017), "The economic consequences associated with integrated report quality: Capital market and real effects", Accounting, Organizations and Society, Vol. 62, pp. 43-64.

Beattie, V. and Smith, S. J. (2013), "Value creation and business models: Refocusing the intellectual capital debate", British Accounting Review, Vol. 45 No. 4, pp. 243-254.

Bernardi, C. and Stark, A. W. (2018), "Environmental, social and governance disclosure, integrated reporting, and the accuracy of analyst forecasts", The British Accounting Review, Vol. 50 No. 1, pp. 16-31.

Boltanski, L. and Thévenot, L. (1999), "The Sociology of Critical Capacity", European Journal of Social Theory, Vol. 2 No. 3, pp. 359-377.

Boltanski, L. and Thèvenot, L. (2006), On justification: economies of worth, Princeton University Press, Princeton.

Bourdieu, P. (1977), Outline of a theory of practice, Cambridge University Press, Cambridge, UK.

Bourdieu, P. (2010), The logic of practice, Stanford University Press, Stanford, USA.

Bouten, L. and Hoozée, S. (2015), "Challenges in sustainability and integrated reporting", Issues in Accounting Education, Vol. 30 No. 4, pp. 373-381. 
Brown, J. and Dillard, J. (2014), "Integrated reporting: On the need for broadening out and opening up", Accounting, Auditing and Accountability Journal, Vol. 27 No. 7, pp. $1120-1156$.

Carnegie, G. D. and Napier, C. J. (1996), "Critical and interpretive histories: insights into accounting's present and future through its past", Accounting, Auditing \& Accountability Journal, Vol. 9 No. 3, pp. 7 - 39.

Chaidali, P. and Jones, M. J. (2017), "It's a matter of trust: Exploring the perceptions of Integrated Reporting preparers", Critical Perspectives on Accounting, Vol. 48, pp. 120.

Chartered Association of Business Schools. (2015), “Academic Journal Guide 2015”, available at: https://charteredabs.org/ (accessed 15 November 2017).

Cheng, M., Green, W., Conradie, P., Konishi, N. and Romi, A. (2014), "The International Integrated Reporting Framework: Key Issues and Future Research Opportunities", Journal of International Financial Management and Accounting, Vol. 25 No. 1, pp. 90-119.

Cohen, J. R., Holder-Webb, L. and Zamora, V. L. (2015), “Nonfinancial Information Preferences of Professional Investors", Behavioral Research in Accounting, Vol. 27 No. 2, pp. 127-153.

Coulson, A.B., Adams, C.A., Nugent, M.N. and Haynes, K. (2015), "Exploring metaphors of capitals and the framing of multiple capitals: Challenges and opportunities for $\langle\mathrm{IR}\rangle$ ", Sustainability Accounting, Management and Policy Journal, Vol. 6 No. 3, pp. 290-314.

de Villiers, C., Rinaldi, L. and Unerman, J. (2014), "Integrated reporting: Insights, gaps and an agenda for future research", Accounting, Auditing and Accountability Journal, Vol. 27 No. 7, pp. 1042-1067.

de Villiers, C. and Sharma, U. (2016), "A critical reflection on the future of financial, intellectual capital, sustainability and integrated reporting", Critical Perspectives on Accounting.

de Villiers, C., Hsiao, P.C.K. and Maroun, W. (2017a), “Developing a Conceptual Model of influences around Integrated Reporting, New Insights, and Directions for Future Research", Meditari Accountancy Research, Vol. 25 No. 4, pp. 450-460.

de Villiers, C., Venter, E. R. and Hsiao, P.C.K. (2017b), “Integrated reporting: background, measurement issues, approaches and an agenda for future research", Accounting \& Finance, Vol. 57 No. 4, pp. 937-959.

de Villiers, C. and Hsiao, P.C.K. (2018), "Integrated Reporting", in De Villiers, C and Maroun, W. (Eds.) Sustainability accounting and integrated reporting, Routledge: Abingdon, UK, pp. 13-24

de Villiers, C. and Maroun, W. (2018), "Introduction to sustainability accounting and integrated reporting", in de Villiers, C. and Maroun, W. (Eds.) Sustainability accounting and integrated reporting, Routledge: Abingdon, UK, pp. 1-12.

Del Baldo, M. (2017), "The implementation of integrating reporting <IR> in SMEs: Insights from a pioneering experience in Italy", Meditari Accountancy Research, Vol. 25 No. 4, pp. 505-532.

du Toit, E. (2017), "The readability of integrated reports", Meditari Accountancy Research, Vol. 25 No. 4, pp. 629-653. 
du Toit, E., van Zyl, R. and Schütte, G. (2017), "Integrated reporting by South African companies: a case study", Meditari Accountancy Research, Vol. 25 No. 4, pp. 654674.

Dumay, J., Bernardi, C., Guthrie, J. and Demartini, P. (2016), "Integrated reporting: A structured literature review", Accounting Forum, Vol. 40 No. 3, pp. 166-185.

Dumay, J. and Dai, T. (2017), "Integrated thinking as a cultural control?", Meditari Accountancy Research, Vol. 25 No. 4, pp. 574-604.

Dumay, J., Bernardi, C., Guthrie, J. and La Torre, M. (2017), "Barriers to implementing the International Integrated Reporting Framework: A contemporary academic perspective", Meditari Accountancy Research, Vol. 25 No. 4, pp. 461-480.

Dumay, J., Guthrie, J. and Rooney, J. (2018), "The Critical Path of Intellectual Capital", in J. Guthrie, J. Dumay, F. Ricceri and C. Nielsen (Eds), The Routledge Companion to Intellectual Capital: Frontiers of Research, Practice and Knowledge, Routledge London, pp. 21-39.

Eccles, R. G., Krzus, M. P. and Ribot, S. (2015), "Meaning and Momentum in the Integrated Reporting Movement", Journal of Applied Corporate Finance, Vol. 27 No. 2, pp. 8-17.

European Parliament and the Council. (2014), “Directive 2014/95/EU “, (accessed 22 January 2018).

Flower, J. (2015), "The international integrated reporting council: A story of failure", Critical Perspectives on Accounting, Vol. 27, pp. 1-17.

Fries, J., McCulloch, K. and Webster, W. (2010), "The Prince's Accounting for Sustainability Project: Creating 21-st Century Decision Making and Reporting System to Respond to 21-st Century Callenges and Opportunities", in Hopwood, A. G., Unerman, J. and Fries, J. (Eds.), Accounting for sustainability. Practical insights. Earthscan, London, pp. 29-46.

García-Sánchez, I. M. and Noguera-Gámez, L. (2017), "Institutional Investor Protection Pressures versus Firm Incentives in the Disclosure of Integrated Reporting", Australian Accounting Review.

Gibassier, D., Rodrigue, M. and Arjalies, D. L. (2018), "“Integrated Reporting Is Like God-No One Has Met Him, but Everybody Talks About Him.": The Power of Myths in the Adoption of a Management Innovations", Accounting, Auditing \& Accountability Journal, Vol. 31 No. 5, article in press.

Gonzalbez, J. M. and Rodriguez, M. M. (2012), “XBRL and integrated reporting: The Spanish accounting association taxonomy approach", International Journal of Digital Accounting Research, Vol. 12, pp. 59-91.

Gunarathne, N. and Senaratne, S. (2017), "Diffusion of integrated reporting in an emerging South Asian (SAARC) nation", Managerial Auditing Journal, Vol. 32 No. 4-5, pp. 524548.

Guthrie, J., Ricceri, F. and Dumay, J. (2012), "Reflections and projections: A decade of intellectual capital accounting research", The British Accounting Review, Vol. 44 No. 2, pp. 68-92.

Guthrie, J., Manes-Rossi, F. and Levy-Orelli, R. (2017), "Integrated reporting and integrated thinking in Italian public sector organisations", Meditari Accountancy Research, Vol. 25 No. 4, pp. 553-573. 
Haji, A. A. (2015), "The role of audit committee attributes in intellectual capital disclosures: Evidence from Malaysia", Managerial Auditing Journal, Vol. 30 No. 8-9, pp. 756-784.

Haji, A. A. and Anifowose, M. (2016), "Audit committee and integrated reporting practice: does internal assurance matter?", Managerial Auditing Journal, Vol. 31 No. 8-9, pp. 915-948.

Haji, A. A. and Hossain, D. M. (2016), "Exploring the implications of integrated reporting on organisational reporting practice: Evidence from highly regarded integrated reporters", Qualitative Research in Accounting and Management, Vol. 13 No. 4, pp. 415-444.

Haller, A. and van Staden, C. (2014), "The value added statement - an appropriate instrument for integrated reporting", Accounting, Auditing and Accountability Journal, Vol. 27 No. 7, pp. 1190-1216.

Higgins, C., Stubbs, W. and Love, T. (2014), "Walking the talk(s): Organisational narratives of integrated reporting", Accounting, Auditing and Accountability Journal, Vol. 27 No. 7, pp. 1090-1119.

House of Commons. (2006), "Companies Act 2006 - Chapter 46", (accessed 22 January 2018).

Humphrey, C., O'Dwyer, B. and Unerman, J. (2017), "Re-theorizing the configuration of organizational fields: the IIRC and the pursuit of 'Enlightened' corporate reporting", Accounting and Business Research, Vol. 47 No. 1, pp. 30-63.

IIRC. (2011), "Towards Integrated Reporting. Communicating Value in the 21st Century", available at: http://integratedreporting.org/wp-content/uploads/2011/09/IRDiscussion-Paper-2011_spreads.pdf (accessed 31 January 2018).

IIRC. (2013), "The International <IR> Framework", available at: https:// integratedreporting.org/ wp-content/uploads/2013/12/13-12-08-THEINTERNATIONAL-IR-FRAMEWORK-2-1.pdf (accessed 31 January 2018).

IIRC. (2015), "The Integrated Reporting journey: the inside story", available at: http://integratedreporting.org/wp-content/uploads/2015/ 07/The-IntegratedReporting-journey-the-inside-story.pdf (accessed 15 November 2017).

IIRC. (2016), "Creating Value. The Cyclical Power of Integrated Thinking and Reporting", available at: http://integratedreporting.org/ (accessed 25 January 2018).

IIRC. (2017), "International <IR> Framework Implementation Feedback", available at: http://integratedreporting.org/ (accessed 25 January 2018).

IIRC. (2017), "Journey to Breakthrough. IIRC Integrated Report 2016", available at: http://integratedreporting.org/ (accessed 8 March 2018).

KPMG. (2013), "Integrated Reporting in practice: The South African story", available at: https://home.kpmg.com/content/dam/kpmg/pdf/2013/04/the-south-africanstory.pdf (accessed 14 November 2017).

Lai, A., Melloni, G. and Stacchezzini, R. (2017), "What does materiality mean to integrated reporting preparers? An empirical exploration", Meditari Accountancy Research, Vol. 25 No. 4, pp. 533-552.

Lai, A., Melloni, G. and Stacchezzini, R. (2018), "Integrated reporting and narrative accountability: The role of preparers", Accounting, Auditing \& Accountability Journal, Vol. 31 No. 5 , article in press. 
Lee, K. W. and Yeo, G. H. H. (2016), "The association between integrated reporting and firm valuation", Review of Quantitative Finance and Accounting, Vol. 47 No. 4, pp. 12211250.

Lodhia, S. and Stone, G. (2017), "Integrated Reporting in an Internet and Social Media Communication Environment: Conceptual Insights", Australian Accounting Review, Vol. 27 No. 1, pp. 17-33.

Macias, H. A. and Farfan-Lievano, A. (2017), "Integrated reporting as a strategy for firm growth: multiple case study in Colombia", Meditari Accountancy Research, Vol. 25 No. 4, pp. 605-628.

Maroun, W. (2017), "Assuring the integrated report: Insights and recommendations from auditors and preparers", British Accounting Review, Vol. 49 No. 3, pp. 329-346.

Maroun, W. and Mcnally, M. A. (2018), "Is not always bad news: illustrating the potential of integrated reporting using a case study in the eco-tourism industry", Accounting, Auditing \& Accountability Journal, Vol. 31 No. 5, article in press.

McNally, M. A., Cerbone, D. and Maroun, W. (2017), "Exploring the challenges of preparing an integrated report", Meditari Accountancy Research, Vol. 25 No. 4, pp. 481-504.

Melloni, G., Caglio, A. and Perego, P. (2017), "Saying more with less? Disclosure conciseness, completeness and balance in Integrated Reports", Journal of Accounting and Public Policy, Vol. 36 No. 3, pp. 220-238.

Milne, M. J., Kearins, K. and Walton, S. (2006), "Creating Adventures in Wonderland: The Journey Metaphor and Environmental Sustainability", Organization, Vol. 13 No. 6, pp. 801-839.

Mio, C. and Fasan, M. (2014), "Beyond financial reporting: A journey from sustainability towards integrated reporting", Journal of Environmental Accounting and Management, Vol. 2 No. 3, pp. 189-203.

Morgan, G. (2006), Images of organization, Sage, London.

Oliver, J., Vesty, G. and Brooks, A. (2016), "Conceptualising integrated thinking in practice", Managerial Auditing Journal, Vol. 31 No. 2, pp. 228-248.

Owen, G. (2013), "Integrated Reporting: A Review of Developments and their Implications for the Accounting Curriculum", Accounting Education, Vol. 22 No. 4, pp. 340-356.

Örtenblad, A., Trehan, K. and Putnam, L. L. (2017), Exploring Morgan's metaphors theory, research, and practice in organizational studies, SAGE, Los Angeles.

Perry-Smith, J. E. and Mannucci, P. V. (2017), "From creativity to innovation: The social network drivers of the four phases of the idea journey", Academy of Management Review, Vol. 42 No. 1, pp. 53-79.

Rambaud, A. and Richard, J. (2015), "The "Triple Depreciation Line" instead of the "Triple Bottom Line": Towards a genuine integrated reporting", Critical Perspectives on Accounting, Vol. 33, pp. 92-116.

Reimsbach, D., Hahn, R. and Gürtürk, A. (2017), "Integrated Reporting and Assurance of Sustainability Information: An Experimental Study on Professional Investors' Information Processing", European Accounting Review, pp. 1-23.

Reuter, M. and Messner, M. (2015), "Lobbying on the integrated reporting framework: An analysis of comment letters to the 2011 discussion paper of the IIRC", Accounting, Auditing and Accountability Journal, Vol. 28 No. 3, pp. 365-402. 
Robertson, F. A. and Samy, M. (2015), "Factors affecting the diffusion of integrated reporting - a UK FTSE 100 perspective", Sustainability Accounting, Management and Policy Journal, Vol. 6 No. 2, pp. 190-223.

Roslender, R. and Nielsen, C. (2017), "Lessons for progressing narrative reporting: Learning from the experience of disseminating the Danish Intellectual Capital Statement approach", Accounting Forum, Vol. 41 No. 3, pp. 161-171.

Rowbottom, N. and Locke, J. (2016), "The emergence of $<\mathrm{iR}>$ ", Accounting and Business Research, Vol. 46 No. 1, pp. 83-115.

Segal, T. G., Segal, M. and Maroun, W. (2017), "The perceived relevance of tax riskmanagement in a South African context", Meditari Accountancy Research, Vol. 25 No. 1, pp. 82-94.

Setia, N., Abhayawansa, S., Joshi, M. and Huynh, A. V. (2015), "Integrated reporting in South Africa: Some initial evidence", Sustainability Accounting, Management and Policy Journal, Vol. 6 No. 3, pp. 397-424.

Silvestri, A., Veltri, S., Venturelli, A. and Petruzzelli, S. (2017), "A research template to evaluate the degree of accountability of integrated reporting: a case study", Meditari Accountancy Research, Vol. 25 No. 4, pp. 675-704.

Simnett, R. and Huggins, A. L. (2015), "Integrated reporting and assurance: Where can research add value?", Sustainability Accounting, Management and Policy Journal, Vol. 6 No. 1, pp. 29-53.

Stent, W. and Dowler, T. (2015), "Early assessments of the gap between integrated reporting and current corporate reporting", Meditari Accountancy Research, Vol. 23 No. 1, pp. 92-117.

Steyn, M. (2014), "Organisational benefits and implementation challenges of mandatory integrated reporting: Perspectives of senior executives at South African listed companies", Sustainability Accounting, Management and Policy Journal, Vol. 5 No. 4, pp. 476-503.

Stubbs, W. and Higgins, C. (2014), "Integrated reporting and internal mechanisms of change", Accounting, Auditing and Accountability Journal, Vol. 27 No. 7, pp. 10681089.

The French Parliament. (2018), "LOI n²010-788 du 12 juillet 2010 portant engagement national pour l'environnement", (accessed 22 January 2018).

Thomson, I. (2014), "Mapping the terrain of sustainability and accounting for sustainability", in Bebbington, J., Unerman, J. and O’Dwyer, B. (Eds.), Sustainability Accounting and Accountability. Routledge, London, pp. 15-29.

Thomson, I. (2015), “'But does sustainability need capitalism or an integrated report' a commentary on 'The International Integrated Reporting Council: A story of failure' by Flower, J", Critical Perspectives on Accounting, Vol. 27, pp. 18-22.

Tweedie, D. and Martinov-Bennie, N. (2015), "Entitlements and Time: Integrated Reporting's Double-edged Agenda", Social and Environmental Accountability Journal, Vol. 35 No. 1, pp. 49-61.

Unerman, J. and O'Dwyer, B. (2010), The Relevance and Utility of Leading Accounting Research, ACCA, London. 
van Bommel, K. (2014), "Towards a legitimate compromise?: An exploration of integrated reporting in the Netherlands", Accounting, Auditing and Accountability Journal, Vol. 27 No. 7, pp. 1157-1189.

Velte, P. and Stawinoga, M. (2017), "Integrated reporting: The current state of empirical research, limitations and future research implications", Journal of Management Control, Vol. 28 No. 3, pp. 275-320.

Venter, E. R., Stiglingh, M. and Smit, A. R. (2017), "Integrated Thinking and the Transparency of Tax Disclosures in the Corporate Reports of Firms", Journal of International Financial Management and Accounting, Vol. 28 No. 3, pp. 394-427.

Vesty, G., Ren, C. and Ji, S. (2018), " $<\mid \mathrm{R}>$ Accounting as a test of worth: A conversation with the Chairman of and <IR> reporting pilot organisation", Accounting, Auditing \& Accountability Journal, Vol. 31 No. 5, article in press.

Vinnari, E. and Dillard, J. (2016), "(ANT)agonistics: Pluralistic politicization of, and by, accounting and its technologies", Critical Perspectives on Accounting, Vol. 39, pp. 2544.

von Alberti-Alhtaybat, L. and Al-Htaybat, K. (2018), "Integrated thinking and reporting at Aramex: case study insights from a global logistics player", Accounting, Auditing \& Accountability Journal, Vol. 31 No. 5, article in press.

WBCSD. (2014), "Integrated Reporting in South Africa: From Concept to Practice", available at: http://wbcsdservers.org/wbcsdpublications/cd_files/datas/capacity_building/ flt/pdf/WBCSD_FLP_2014_Integrated Reporting-South Africa[1].pdf (accessed 15 November 2017).

Zhou, S., Simnett, R. and Green, W. (2017), "Does Integrated Reporting Matter to the Capital Market?", Abacus, Vol. 53 No. 1, pp. 94-132. 